\title{
Cosmopolitanism and Unipolarity: The Theory of Hegemonic Transition
}

(Forthcoming in the Critical Review of International Social and Political Philosophy

Doi: 10.1080/13698230.2020.1766815)

\author{
Jelena Belic ${ }^{1}$ \\ Department of Political Science, Central European University, Budapest, Hungary \\ Zoltan Miklosi $^{2}$ \\ Department of Political Science, Central European University, Budapest, Hungary
}

\begin{abstract}
Cosmopolitans typically argue that the realization of cosmopolitan ideals requires the creation of global political institutions of some kind. While the precise nature of the necessary institutions is widely discussed, the problem of the transition to such an order has received less attention. In this paper, we address what we take to be a crucial aspect of the problem of transition: we argue that it involves a moral coordination problem because there are several morally equivalent paths to reform the existing order, but suitably placed and properly motivated political agents need to converge on a single route for the transition to be successful. It is, however, unclear how such a convergence can take place since the duty to create global institutions does not single out any coordination point. We draw on the so-called theory of hegemonic stability to address this problem and conceptualize what we call the hegemonic transition. From an explanatory point of view, we rely on the theory's insights to explain how a hegemon may contribute to the creation of a rules-based international order by providing salient coordination points and accordingly, enabling coordination among states. From the normative point of view, we identify necessary conditions for the hegemonic transition to be morally permissible. To the extent that these conditions obtain, other states have pro tanto moral reasons to follow the salient coordination point provided by the leading state.
\end{abstract}

Keywords: cosmopolitanism, global justice, unipolarity, hegemony, transition, coordination problems

\footnotetext{
${ }^{1}$ Jelena Belic, belicsjelena@gmail.com

2ZZoltan Miklosi, miklosiz@ceu.edu
} 


\section{Introduction}

Cosmopolitans usually think that a rules-based international order where global institutions set up fair terms of international cooperation among different kinds of agents is morally desirable. Recognizing that several pressing issues necessitate global cooperation (climate change, migrations, global poverty and inequality), cosmopolitans are supportive of broadening and deepening international political integration to tackle these issues. Despite generally accepting the need for global institutions, cosmopolitans rarely engage with the problem of the transition toward such an arrangement. ${ }^{1}$ This is unfortunate because the transition toward a more integrated international order raises important normative theoretical problems of its own. Specifically, the problem of transition constitutes a moral coordination problem: to create a cosmopolitan international order, duty bearers ought to coordinate upon a single point, but it is usually not clear what the point should be. In this paper, we aim to elaborate on the nature of the transition problem and to offer a possible solution to it.

In developing our solution, we will use insights from the relevant empirical IR literature. The question of how international orders emerge is at the core of IR scholarship. In this respect, the theory of hegemonic stability (HST) is of particular relevance. In a nutshell, the theory holds that 'the presence of a single dominant actor in international politics leads to collectively desirable outcomes for all states in the international system' (Snidal, 1985, p. 579). While the theory has been challenged on different grounds, we will rely on one part of it that seems the most plausible - the one that concerns the emergence of international orders. Following the HST, we will argue that a hegemonic state may play a coordinating role in transitioning toward a cosmopolitan international order. $^{2}$ We will call this transitional path hegemonic 
transition. ${ }^{3}$ To the extent that there is a hegemonic state and it performs this coordinating role in a satisfactory manner, other states have defeasible but strong pro tanto moral reasons to join the coordinating scheme.

This solution to the problem of transition may strike many cosmopolitans as counterintuitive. Since most of them believe that the current, unipolar world order is severely unjust, it might seem that the hegemonic state, which has been crucial in creating and maintaining the order, is the proper object of moral blame rather than of support. Moreover, hegemony involves an extremely unequal distribution of power among states that cosmopolitans find morally troubling. Hence, they seem to have strong reasons to reject hegemony as a transitional path toward global cosmopolitan institutions. In this paper, one of our aims is to make cosmopolitans reconsider these reservations. While we do not deny that the current leading state, i.e. the United States (and other powerful ones), bears moral responsibility for the unjust features of the current order, we argue that this is compatible with it playing a leading role in a cosmopolitan transition. ${ }^{4} \mathrm{We}$ agree that a hegemonic order is incompatible with cosmopolitan justice, but we argue that under certain conditions a hegemonic transition is a morally permissible way for a cosmopolitan order to be established. We also claim that cosmopolitan arguments in favor of the rules-based international order also provide reasons in favor of the hegemonic transition as compared to a path that would start from scratch, as it were.

The argument runs as follows. We start by explaining why cosmopolitans endorse a rules-based international order and outline the ideal endpoint we call theGlobal Political Union. We then compare the current international system, which we will refer to as the Liberal World Order with the GPU. Next, we present the problem of transition toward the GPU as a moral coordination problem. We then move to resolve 
this in two steps. First, we argue that there are good reasons to take the LWO as the basis for the transitional process to build on. Second, by drawing on the theory of hegemonic stability, we explain the role the hegemon can play in creating the cosmopolitan order. Based on this, we theorize the notion of hegemonic transition as a transition led by a hegemonic state. ${ }^{5}$ We then specify the conditions under which a hegemonic transition is morally permissible. To be specific, we do not claim that there is no conceivable transition path that could be morally superior to the hegemonic transition; we only argue that if and when the hegemon performs its coordinating role adequately, other states have pro tanto but defeasible moral reasons to follow its lead. In the end, we address some objections to our view.

\section{Cosmopolitanism and Institutional Design}

Cosmopolitanism is the view that the same principles of justice apply to all persons globally, just in virtue of their personhood, and regardless of their more specific institutional, communal, national or other circumstances (Caney, 2005). This generic understanding of cosmopolitanism is a claim about the scope of the principles of justice, not about their content. That said, virtually all cosmopolitans agree that at the very least, justice requires respecting, protecting and fulfilling the human rights of all persons as well as providing some measure of socioeconomic justice globally. For the purposes of this paper, it is not necessary to engage in the substantive debates about the correct principles of global socioeconomic justice. Instead, we simply assume that some version of cosmopolitanism is true.

Taken in this generic form, cosmopolitanism is not committed to any particular view about global institutional design. The usual assumption is that the argument regarding global institutional design should proceed instrumentally; once a suitable 
position on the normative standards for evaluating institutions globally has been identified, one can develop a position regarding what institutional scheme would best approximate those standards (Pogge, 1992; Caney, 2006). At the extreme, it is conceivable that cosmopolitan principles could be satisfied under the current system of nation-states if only national political communities and their elected governments embraced cosmopolitan views. ${ }^{6}$ Nonetheless, it is unlikely that even an improved version of the state system provides the best prospects for achieving cosmopolitan goals; virtually all cosmopolitans (and many non-cosmopolitan liberals) agree that international or global institutions much more robust than the existing ones are necessary for making significant progress towards more just world order. ${ }^{7}$ While some argue straightforwardly for world government, others advocate for a global governance system in which an increasing number of competences is transferred from the state level towards international institutions. Once again, we wish to remain agnostic on the need for or desirability of world government. However, we do assume that a form of thoroughly institutionalized global political cooperation (consistent with but not requiring a world government) provides the best prospects for approximating the principles of cosmopolitan justice. ${ }^{8}$

Our argument incorporates an additional, theoretically inspired feature that further restricts the range of institutional arrangements that are likely to pass the cosmopolitan test. This feature is the Kantian-inspired claim that justice requires, on any scale, the establishment of a single legal system on that scale complete with authoritative institutions to make, interpret, and enforce rules. In a nutshell, the Kantian insight is that the abstract principles of justice by themselves underdetermine what specific conduct individuals must follow in order to secure just outcomes, and therefore they also underdetermine the content of law; several different legal arrangements may 
be equivalent from the point of view of justice. ${ }^{9}$ However, for justice to be secured, it is necessary that all individuals concerned converge on the same arrangement out of those equivalent from the point of view of justice. This implies that justice requires authoritative institutions even among well-motivated individuals because their sense of justice alone is not sufficiently action-guiding, and they may disagree about the correct principles of justice or about the best way to realize them. Authoritative decisionmaking procedures are therefore necessary to pick one (and only one) among the arrangements that are equivalent from the point of view of justice. The Kantian insight suggests that securing global justice requires, as a necessary condition, the existence of authoritative institutions to make rules and enforce them at the global scale. ${ }^{10}$

To make this description less abstract, it may be productive to think of it along the lines of the most developed regional cooperation in modern history, i.e. the European Union. To be sure, the EU faces severe challenges these days, but from a historical perspective, it is a uniquely successful regime of institutionalized cooperation in achieving peace, economic prosperity, and the fulfillment of human rights. The institutional order favored by a cosmopolitan ideal of justice might resemble something like a much-improved European Union writ large, on a global scale. While we cannot spell out the details of such a Union, we believe that the following features are rather uncontroversial from a cosmopolitan point of view. The Union would include shared sovereignty over highly significant domains of policy-making, and it would have a common legal system backed up by judicial institutions complete with enforcement mechanisms. Moreover, the Union would, by hypothesis, involve a significant transfer union to achieve socioeconomic justice globally. We will refer to this arrangement as the Global Political Union (GPU). 
Cosmopolitans typically focus on identifying principles of justice globally as well as on global institutional arrangements that could approximate them. The process of transition to such an arrangement, however, has received insufficient attention. ${ }^{11} \mathrm{We}$ will turn to this problem shortly. Before doing so, we would like to clarify the connection between the present world order and the cosmopolitan project. The clarification is necessary for two reasons. First, a theory of cosmopolitan transition must give an account of the normatively significant characteristics of the current international order to assess its moral distance from the desired end-state, to see which of its elements could potentially serve as building blocks of the latter and which ones are obstacles to it. And second, such juxtaposition may be helpful to assess whether the best prospects of achieving the end-state are offered by an evolutionary path from the current order, or rather by starting from scratch, as it were. To be sure, in one sense the transition necessarily takes as its starting point the current order, since this is the 'here' from which we morally have to get 'there'. Nonetheless, it is a further and open question whether the most appealing route is one that builds on the current order or one that starts by dismantling it. ${ }^{12}$ We will argue for the first of these alternatives. We provide a very brief normative assessment of the current institutional order as compared to the sketch of the GPU outlined above. Then, we turn to the problem of transition proper.

\section{The Global Political Union and the "Liberal World Order"}

It has become customary to refer to the post-war international order as the Liberal World Order (LWO) (Ikenberry, 2018). While this label invites various misunderstandings, several features of the system make it at least partly appropriate. For instance, the creation of the United Nations made international peace and cooperation the central goals of the international system; human rights have become deeply 
entrenched as standards to which states are held to account, even if the actual level of human rights fulfillment is very far from what liberals (cosmopolitan and noncosmopolitan alike) would wish. The LWO has also achieved rule-governed cooperation and conflict management in many central areas, most significantly in trade. Therefore, even if the LWO may not be an essentially liberal order, it is one with significant liberal characteristics and aspirations. As such, it shares some features with the arrangement that we have referred to above as the Global Political Union, both at the level of normative ideal and of institutional practice.

However, the LWO is not, nor does it aspire to become, the GPU. For example, shared sovereignty and institutionalized cooperation for the purposes of global socioeconomic justice is not even among its aspirational goals, let alone an avowed shared norm to which political actors could be held account to. The current system takes it for granted that sovereign states are the main building blocks of the international order and aspires to create peaceful order primarily in interstate relations, and only secondarily (if at all) in relations among persons qua persons globally. By contrast, the GPU has no commitment to the principle of state sovereignty; instead, it is primarily concerned with just relations among all persons. In sum, the two systems share the commitment to human rights and rules-based order, while they differ in the way they conceive of the goals of such an order and the ultimate standards by which it is to be judged.

Given these differences and similarities with the GPU, how should cosmopolitans think of the LWO? Clearly, they cannot be neutral between the LWO and its alternatives as commonly understood, i.e. a more "Westphalian" order with virtually unconstrained state sovereignty and balance-of-power politics, or some form of international anarchy. Cosmopolitans must see the LWO as a significant improvement 
over these alternatives. But this says nothing about the role it can play in the cosmopolitan project. While proponents of the GPU must think that the LWO is preferable to its historical alternatives if those are the only options, this need not commit them to improve the LWO as the preferred path to the GPU. They may think, for instance, that the LWO's commitment to the principle of state sovereignty makes it a historical cul-de-sac, an improvement as compared to a pure Westphalian system but not an appropriate basis for further progress because of the likely path-dependencies that an LWO-based transition may create. In short, they may think that the GPU must be built from scratch rather than on the back of the LWO.

We will argue that there are important reasons to build on the LWO and proceed by way of gradual reforms. Specifically, any theory of cosmopolitan transition has to recognize that the situation in which we contemplate the path to the GPU is not one of institutional vacuum, but it is an already highly structured arrangement. This must be taken into account not only from the point of view of the costs of different transitional paths but also from the point of view of the structures of political agency that are available for reform. ${ }^{13} \mathrm{~A}$ theory of transition has to consider these factors when assessing and comparing different transitional paths. ${ }^{14}$ In what follows, we will offer normative and empirical reasons in support of what we will call 'hegemonic transition'. We will start by explaining the problem of transition from a normative point of view and move to discuss more empirical considerations.

\section{The Problem of Transition}

From the point of view of normative analysis, the problem of transition presents theoretical challenges of its own. The crucial challenge is the following. Various agents are under moral obligations to take steps towards the realization of the cosmopolitan 
ideal which we identified as the Global Political Union, but there are multiple (morally equivalent) transitional paths that they may pursue. ${ }^{15}$ For a successful transition to the GPU to take place, however, all or at least most relevantly placed agents have to adopt the same transitional path. In other words, they have to coordinate their actions, but their moral obligations do not single out any particular coordination point. Note that this holds irrespective of the motivations they might have - coordination problems can occur even among well-motivated agents ready to do what they morally ought to do. In a nutshell, the problem of cosmopolitan transition can be characterized as a moral coordination problem. ${ }^{16}$ It is moral since it concerns the creation of a morally desirable cosmopolitan world order, rather than the pursuit of self-interest. These considerations reveal the difficulty of reforming the existing order: while global institutions are needed to resolve coordination problems among different agents, the creation of such institutions triggers coordination problems of its own.

One might immediately object that the existing international institutions, most notably the UN, can provide salient coordination points in transitioning toward the GPU. ${ }^{17}$ To be sure, the role of the existing international institutions should not be underestimated since they provide important channels of communication and consultation among states, and also facilitate their cooperation. This is, however, not enough to establish that they can also secure salient coordination points for their own reform. Reform proposals and the political momentum to implement them typically originate from the states. Despite the existence of several international institutions, coordination problems among states are still prevalent and especially pressing in the context of global institutional reforms. ${ }^{18}$ It follows that the coordination problem that is at the heart of the cosmopolitan transition is to be resolved by states themselves. It is in 
this regard that the IR literature on how international orders emerge and how transitions in the order take place becomes relevant. We turn to this now.

\section{IR and the Creation of International Orders}

The problem of the creation and maintenance of international orders has been the subject of intense debates among IR scholars. This fundamental issue in IR theory is highly contested, and therefore it is unlikely for a single conclusion to emerge. To the extent that our argument relies on an empirical premise drawn from this literature, this is a disadvantage since the plausibility of our conclusions will be affected by the contested nature of that premise. Nonetheless, we take comfort in the fact that the alternative hypotheses are also controversial, and the one that we rely on does not seem to be more contested then the alternatives. Since some empirical assumptions are necessary, the best we can do is to make assumptions that have significant support within the relevant IR literature and that we find convincing, and admit the limitations that this imposes on the conclusions that we make.

Our empirical premise builds on what is sometimes referred to as the 'theory of hegemonic stability' (HST). At first approximation, the theory holds, in the useful summary of one of its critics, that 'the presence of a single, strongly dominant actor in international politics leads to collectively desirable outcomes for all states in the international system. Conversely, the absence of a hegemon is associated with the disorder in the world system and undesirable outcomes for individual states' (Snidal, 1985, p. 579). The theory is usually seen as making at least two overarching claims: first, the hegemony normally facilitates the creation of order, and second, hegemony is also necessary for the continuous maintenance of order. The two claims are not necessarily interdependent, and not everyone who accepts the first is convinced by the 
second (Keohane, 2005; Ikenberry, 2018). It is entirely conceivable that once an order has been established and its benefits generally enjoyed, the erosion of the hegemony of the leading state that had been instrumental in creating it does not undermine its successful operation.

Again, the HST makes claims not simply about how the presence of a hegemon affects outcomes within the confines of an international order, but also about the emergence of international orders in the first place. Thus, one of the foremost theorists associated with the HST, Robert Keohane, has famously argued that the dominant economic and military position of the United States in the post-war world (i.e. the Western part of it) was a necessary condition of the emergence of the rules-governed, significantly institutionalized international order and that the weakening of US hegemony is associated with corresponding disturbances within that order (Keohane, 2005). ${ }^{19}$ A later, distinctively liberal development of the theory further holds that the unipolar position of the US, combined with its internal liberal democratic institutions, has been responsible for the significant liberal characteristics of the Liberal World Order, especially the fact that it includes multilateral institutions that constrain the hegemon nearly as much as the less powerful states (Ikenberry, 2012). ${ }^{20}$ This refinement of the theory will be of special interest for us, since our normative focus is not simply on the creation and maintenance of any kind of order, but of such an order that has certain normatively desirable characteristics, including institutionalized political cooperation, the rule of law, the entrenchment of human rights, and socioeconomic justice.

It is noteworthy that we are not committed to the strong claim that hegemony is either necessary or sufficient for the creation of a rules-governed multilateral liberal order. The first would mean that no such order is possible without a hegemon, while the 
second would imply that the existence of a hegemon automatically leads to the creation of such an order. We do not have great confidence in the first claim, and we have no interest in the second. Our premise includes only the more modest claim that the existence of a hegemon is normally an important facilitating condition of creating a rules-governed multilateral liberal order.

As stated above, we cannot engage with the vast IR literature on hegemony and order. Nevertheless, it is important to briefly describe the key mechanisms that are putatively responsible for the link between hegemony and the creation of multilateral international institutions. Before doing so, it should be noted that international order may come in different varieties, and under different circumstances, the hegemon has incentives to forge different types of relations. The two fundamental types of international order open to a hegemon are the imperial and liberal ones. Imperial orders are characterized by the formal subordination of less powerful states to the hegemon, by the fact that they are sustained mainly through coercion or the threat of coercion, and the hegemon tends to maximally exploit the power asymmetry between it and the other states. 'Liberal' orders are liberal only in the weak sense of mostly operating through mutually agreed-upon rules and institutions that bind the hegemonic state as well, that they recognize the formal equality of all states, and that they generally favor openness of trade and economic activity.

One question therefore that has preoccupied IR scholars are the circumstances that favor the creation of a liberal (aka multilateral order) rather than an imperial one. Such a choice may appear puzzling, since by definition the leading state enjoys vast bargaining advantages vis-à-vis any other state in bilateral relations, and therefore may seem to have an interest in pursuing such putatively exploitative relations. But it is entirely possible that a hegemon chooses multilateralism. This choice can be explained 
by two types of considerations: on the one hand, there are some external considerations that are quite independent of the specific characteristics of the leading state; on the other hand, certain considerations apply only in the case of hegemons with particular internal characteristics.

Generally, a multilateral order that is created with significant input from the less powerful states and whose rules are to some extent negotiated rather than unilaterally imposed reduces the costs of enforcement for the leading state. It does not have to rely on near-constant coercion or threat thereof and consequently might reduce its military expenditure in favor of other socially desirable goals. Second and relatedly, multilateralism enhances the perceived and real legitimacy of the order, making it more attractive to the less powerful states thus creating incentives for them to join. Third, by accepting some limits on its policy autonomy by submission to the common rules, the leading state may secure favorable policies from other states at lower costs than would be available in an imperial order. These considerations seem to make multilateralism attractive to any kind of hegemon regardless of its internal characteristics.

When it comes to internal considerations, the HST suggests that a hegemon's internal norms will significantly affect the type of international order it aspires to create. If the leading state is internally liberal, there will be normative pressure to adopt similar norms internationally as well (see also Doyle, 1983). Second, if the leading state is more economically developed than most of its trading partners, then it will have an interest in free trade in general, which is easier to achieve through multilateral institutions, since even a hegemonic state may not be able to impose such an order on most of the states it wants to trade with. Third, the more interdependent the world economy is, the more difficult it becomes to settle disputes and harmonize national policies on a case-by-case basis, bilateral bargaining or imposition, and the more incentives there will be to create 
general rules for harmonization, dispute settlement, and conflict management. As the volume of policy areas that states need to coordinate upon increases, the more pressing the need for robust, rules-based cooperation becomes. Fourth, the leading state may anticipate that its economic and technological primacy may not last forever, and other states may catch up in the foreseeable future. ${ }^{21}$ The prospect of losing its dominant position may provide incentives for the leading state to 'lock-in' favorable terms of cooperation by institutionalizing them, thus making them permanent or at least less amenable to change even in the period when their advantage will have been eroded (Ikenberry, 2012, pp. 102-109).

As we have repeatedly noted, these claims are far from universally accepted among IR scholars. Nonetheless, they do provide a plausible analysis of the emergence of the current world order, which cannot be easily dismissed. In any case, our argument about the cosmopolitan transition does not require a fully generalizable empirical theory about the creation and maintenance of international order. It suffices for our purposes if it can be established with some plausibility that the existence of a hegemonic state with significant internal liberal-democratic characteristics is a facilitating condition for the creation and further transformation of a rules-based, multilateral international order. ${ }^{22}$ If as much as this is made plausible, then an important factor in considering different transition paths to the GPU has been introduced. To wit, the empirical literature provides some support for the idea that a transition led by a hegemonic state $-a$ hegemonic transition, as we will call it - has somewhat better prospects than its alternatives.

\section{Conceptualizing Hegemonic Transition}


In the previous section, we explained, following some of the basic precepts of the HST, how a hegemon can play a crucial role in creating the new international order. We called this the hegemonic transition, i.e. the transformation of the LWO led by a hegemonic state. With all possible empirical limitations such a hypothesis might face, in this section, we will explain how it can address the normative problem of transition that we have defined as the problem of moral coordination. Recall that the problem of transition essentially concerns the under-determined nature of the transition path that the relevantly placed actors face. Given that there is no obvious coordination point, there is a risk that agents will pursue different coordinating strategies and consequently, fail to coordinate.

In our view, the hegemonic transition, arguably, can not only solve these problems in a practical sense but, under certain conditions, it can do so in a morally permissible manner. Under the conditions of hegemonic transition, not all agents are symmetrically placed, and therefore not all the otherwise morally equivalent options available to them are practically equivalent as well. In particular, the option adopted by the hegemonic state provided that it is within the morally eligible $\operatorname{set}^{23}$ may constitute a salient coordination point. In a situation where different (well-motivated) states contemplate different transition paths, information about the option adopted by the leading state will have special significance, as that option provides the best practical prospects of successful coordination. This suggests that when it comes to coordination, states may play two distinct roles: providing a salient coordination point for others and adopting such a point provided by the hegemonic state.

When it comes to hegemon, the main idea is that its great capacities entail great responsibilities, which in our view, include the following. First, the leading state faces a special responsibility to adopt a morally acceptable option because its choice will 
significantly affect the behavior of other, similarly motivated states. Second, the hegemon should pursue, to use Ikenberry's term - a rules-based foreign policy and conduct international actions through multilateral institutions. In the context of transforming the present LWO, this would mean that the hegemon should initiate and coordinate changes within the framework of the existing rules-based international order instead of trying to make deals with particular countries or impose its choice unilaterally. Additionally, the hegemon should employ consultative mechanisms allowing other states to participate in creating and implementing integrative agenda. We can think of such consultations as an 'inegalitarian inclusion': the hegemon should include others in the creation and implementation of the integrative agenda, but such inclusion may fall short of equal participation. Importantly, inegalitarian inclusion is one of the necessary legitimating conditions of the hegemonic transition, even if it falls below the threshold of justice. We will come back to this. Third, the hegemon should ensure that there are relations of trust between it and other states, and also among other states themselves. Such trust can be built by, for instance, the hegemon following rules it helped create, and so assuring others of its benign and cooperative intentions.

Once the leading state had made its choice in a manner described above, the other states have defeasible but strong pro tanto reasons ${ }^{24}$ to adopt the same option even if it is not the one that they initially preferred. The coordination option proposed by the hegemon is salient because it is more likely that a higher number of states will follow it. In this sense, the hegemon's choice provides a way out of the coordination problems states face and consequently, a way for them to comply with their otherwise underdetermined transitional duties.

One might object that states may still disagree about the coordination point, and hence, reject the one proposed by the hegemon, no matter how salient it is. We should 
here distinguish between two different cases. Some states may reject the proposed coordination because they are unwilling to do their share of creating the GPU. Alternatively, they may be inclined to reject it because they think there are morally better coordination options available. We put the first case aside for now, as we will return to the problem of moral motivation later. As for the second case, our view is that once the hegemon, after proper consultation and deliberation, has adopted an option that is at least within the morally acceptable range, then this is a normally decisive reason for other states to adopt the same option, even if they remain convinced that their own proposal is morally better. This is so because they have moral reasons to prefer secondbest coordination over no coordination, and adopting the hegemonic option provides the best chance of avoiding no coordination. ${ }^{25}$ Insisting on their own proposal, by contrast, increases the probability of the outcome ranked last from the moral standpoint, i.e. no coordination. Therefore, by adopting the hegemon's alternative for coordination, the other states are likely to better comply with the moral reasons that apply to them independently than if they were to try to follow these reasons directly. ${ }^{26}$

The preceding discussion may convince some readers that a hegemonic transition that builds on the existing structures of the LWO should not be ruled out from the start as a morally acceptable transition path to the GPU. But does it provide support for the case that it could be a morally preferred path over dismantling the LWO and starting all over? The question is difficult to assess because of the lack of clarity regarding what it takes to start from scratch. It may mean, more modestly, to dismantle all existing international institutions and the structure of international law and start building a new system that conforms to cosmopolitan principles of justice with the participation of states in a fair procedure. More radically, it may mean dismantling the existing states as well and building the GPU with the participation of persons directly. 
The radical proposal is hard to even contemplate, let alone to take seriously. As for the more modest one, it seems to us that the considerations adduced above not simply support the hegemonic path but also advise against 'starting over'. Central to our argument is the need for, and difficulty of, achieving coordination in international political action even among well-motivated agents and this applies to the alternative scenario, too. But while the existing structures of the LWO, however imperfect, provide resources for the coordination and for building trust among states, these would be sacrificed in the 'starting over' scenario. Furthermore, the creation of such coordinationenabling structures is a contingent and fragile historic achievement, with no guarantee that it can be easily replicated if one starts all over again. For this reason, we take it that there are pro tanto reasons that favor the hegemonic transition over the 'starting from scratch' alternative. Note that this does not make our proposal conservative since gradual reforms can, over time, lead to a global arrangement radically different from the current one (i.e. GPU without a hegemon).

Before we turn to some important objections, let us address an issue that surely occurred to some readers by now: the question of the permissibility of the use of force by the hegemon to achieve coordination. It seems to us that the primary means for the hegemon to discharge its special responsibility to forge the cosmopolitan order is that of shaping the options available to others, creating incentives for them to take its preferred options, and possibly increasing the costs of not taking them. And if the other states are at least partially well-motivated, they will see that they have strong reasons to adopt those options for coordination (as long as they are within the morally acceptable set). This clearly falls short of full-blown authority in the Razian sense, ${ }^{27}$ in which the authority's decisions constitute exclusionary reasons for those subject to it, and also include the right to use force to ensure compliance. But is this limitation warranted? Is it 
not the case, by the logic of our argument, that the hegemon's privileged position to lead the transition, combined with the immense importance of achieving the GPU, ground the hegemon's full-blown authority including its right to coerce others into compliance?

It seems to us that the general answer is 'no'. As far as the issue of building more robust and more just global institutions is concerned, the hegemon's justified influence is limited to incentives. The basic expectation is that enough states will fall in line to create a critical mass, and to increase the gravitational pull of the evolving union, making it more and more attractive for the still reluctant states to join. ${ }^{28}$ However, we do not want to entirely sidestep the question of force. Since the hegemon's alleged right to force other states to join the GPU is a special case of the more general right to enforce cosmopolitan principles, the case of human rights and humanitarian interventions may be instructive here. As the norm of human rights has become more entrenched within the LWO, the permissibility of humanitarian intervention to stop mass violations has also become more widely accepted, at least in principle. It is a reasonable expectation that as the GPU continues to evolve and more and more states join in, the range of norms around which similar consensus may be formed also broadens, and as a result, the scope for the legitimate use of force, either by the hegemon supported by other states or by all of them collectively, also expands. Be that as it may, it seems to us that the permissibility of the use of force outside gross human rights violations is conditional on broad consensus around such norms. ${ }^{29}$

\section{Objections}

The idea that hegemonic transition is a permissible transitional path from the LWO towards the GPU will likely attract numerous objections. First, it may be objected that 
the hegemonic transition allows the most powerful state to skew the cosmopolitan order to fit its particular interests. We call this the hijacking objection. Second, one might worry that the hegemon would be unwilling to pursue the socio-economic transformation of the present world order. We call this the economic inequality objection. Third, the hegemonic transition exhibits an extremely unequal distribution of power, and this may be incompatible with cosmopolitan egalitarian premises. We will call this the unequal distribution of power objection. The first and second objections are both related to the moral motivation of the hegemon, so we will discuss them together. The third objection raises issues of procedural legitimacy and injustice and therefore needs separate treatment.

\section{The Problem of Moral Motivation}

Both the hijacking objection and the economic inequality objection are based on accurate observations. The hegemonic state, i.e. the U.S. is clearly enjoying significant advantages within the LWO that it will not have once the GPU is established. These advantages include having privileged positions in important institutions (U.N., the International Monetary Fund, the World Bank), and in the fact that the LWO does not require wealthy nations to share their wealth with others. Therefore, the non-moral interests of the U.S. and other high-income countries are in tension with the aspirations of the GPU. Why would it lead the charge to create it?

The objection is grounded in a valid insight. Up until this point, our argument simply assumed that political actors (including the hegemon itself) are capable of and normally willing to act upon moral reasons. Now it is time to subject this assumption to critical scrutiny. One might wonder whether the assumption is even necessary for our argument to work; after all, we explained above how the pursuit of enlightened self- 
interest can lead the hegemon to adopt rules-based, liberal multilateral arrangements. Can't one make a similar argument about the GPU? It seems to us highly unlikely that enlightened self-interest alone can take us from the LWO to the GPU; it seems possible that it can lead to the establishment of more robust global institutions, but there is no strong reason to believe that they would also be more just ones. While in some areas (e.g. climate change) self-interest may align with the demands of morality, this seems much less likely in other domains, chief among them socioeconomic equality. Therefore, moral motivation seems necessary for any conceivable path to the GPU. For this reason, we are permitted to assume that agents or at least some of them, are wellmotivated; if we were to give it up, we would be declaring the GPU impossible to achieve, and our whole exercise to be pointless. By the same token, the assumption is not specific to the hegemonic account of transition; all plausible theories of cosmopolitan transition must assume it, too. ${ }^{30}$ At the same time, the assumption is not fanciful; there is a significant body of evidence suggesting that the international behavior of liberal democracies is partially shaped by the normative ideas of their domestic politics (Doyle, 1983).

But this does not settle the issue entirely. One might still worry that our motivational assumption is too idealizing. In response, we make three points. First, given the partial convergence of enlightened self-interest and moral reasons, it may be possible to harness the former in the service of the latter (Ulas, 2016). Second and more importantly, we note that our motivational assumption is not as demanding as it may first appear. The hegemon need not be motivated directly by full-fledged cosmopolitanism in order to make progress towards it. It may be moved by an evolving series of intermediate ideals that bridge the normative space between the LWO and the GPU. The ideal that motivates it initially could be one that is quite close to the LWO, 
only to be superseded by another intermediate ideal once the first is reached. And with each new intermediary stage, motivations can change too - an agent may be motivated to act in specific ways later provided it acts in certain ways first. ${ }^{31}$ While noncosmopolitan moral reasons may dominate at the beginning of the hegemonic transition; as the transition progresses, cosmopolitan moral reasons will become increasingly salient. This process can receive further support from the distinctive logic of integrative processes - integration in one policy area often necessitates integration in another. ${ }^{32}$ The evolution of the EU shows, for instance, how the moral motivation of founding member states to secure peace in Europe led them to keep expanding the area of supranational integration starting from a very limited economic cooperation in producing coal and steel, all the way down to the existing union, and leaving open the further integration path. In light of this, it is possible that states, including the hegemon, end up in a world order that none of them aimed for at the beginning of the process. Third, it is not necessary to assume that all the relevant actors are well-motivated; it may be sufficient if the hegemon and some other key states are. ${ }^{33}$ In sum, it seems to us that our motivational assumption is both necessary and more empirically plausible than may first appear.

\section{The Unequal Distribution of Power Objection}

Another, related objection concerns the process of hegemonic transition itself, rather than its likelihood of reaching an acceptable outcome. It is a natural suggestion that the egalitarian commitments of cosmopolitanism should be reflected in the transition process as well, which is clearly not the case with the hegemonic transition. The problem of epistemic injustice is especially pressing. In response, we would like to make two points. First, the focus of the egalitarian commitment of cosmopolitanism are individuals, not states. It is the equal opportunity for the political power of individuals 
that can be plausibly associated with cosmopolitanism and such equality is in principle compatible with the unequal distribution of power among states. It may be in line with egalitarian commitments that more populous states that represent more people should have more influence on the shape of the global order. ${ }^{34}$ Therefore, the fact that the hegemon, which in all conceivable scenarios is a large and populous state, has an unequal role in the transition is not necessarily damning from a cosmopolitan standpoint.

However, this response goes only so far. There are very large states with huge populations that are quite poor by the standards of advanced economies, and which have disproportionately little influence in international politics due to various historical circumstances, including colonialism. ${ }^{35}$ Such disparities cannot be justified on the same grounds as the disparity between the United States and, say, Belgium may be accounted for. Therefore, it has to be granted that some aspects of the unequal power of the hegemon in the transition is morally suspect. This brings us to our second point: all inequalities of political power stand in need of justification, and at least part of the justification will be instrumental in character. That is, the inequality of power is justified, at least partly, if it is necessary to achieve morally better political outcomes, or if it at least significantly increases the probability of these outcomes. ${ }^{36}$ If our empirical assumption that the hegemonic path increases the likelihood of success in creating a cosmopolitan order, then one crucial piece of the justification of the hegemon's unequal position is established.

One might object here that a path involving an arrangement like the League of Democracies represents a more inclusive and democratic alternative to the hegemonic path (Pasternak, 2012). And if such an alternative is, in fact, feasible, then that weakens the moral case for the hegemonic path. In response, we do not think of the League as a 
sui generis alternative to the hegemonic transition since it would require a leading state to facilitate the creation of the League in the first place. Hence, instead of being its alternative, it is instructive to think of the League as one of the possible stages within the hegemonic transition.

Now, we are not claiming that the probability of achieving the desired outcome is normally sufficient to justify a transition path or that 'outcome trumps procedure'. This is why we emphasize that the hegemonic transition ought to be as consultative and multilateral as possible, and oriented towards building trust among the agents involved. However, it should be noted that the cosmopolitan transition is a non-standard case insofar that the core of the problem is precisely that there is no established institutional procedure for building cosmopolitan institutions. Therefore, well-motivated agents will often face a choice between making progress towards the GPU in ways that are not sanctioned by formal legitimate procedures, and not making any progress at all. It is in this specific setting that we propose the acceptability of the hegemonic path. ${ }^{37} \mathrm{We}$ also note that under such conditions, inegalitarian inclusion can serve as one of the legitimating conditions of the hegemonic transition. This legitimating condition is admittedly weak, and the path to a substantively just arrangement inevitably leads through procedural injustice. It is the responsibility of the hegemon to mitigate this as much as possible, and perhaps of the GPU, once it is established, to compensate for it. However, we recognize that even with ex-post compensation, there is something genuinely morally regrettable about the procedural injustice of hegemonic transition that is not fully remedied by the expected outcome.

We add a final qualification. It seems to us that as the hegemonic transition progresses and the world order moves closer to the cosmopolitan ideal, the demands of procedural legitimacy and justice become gradually more stringent. The progressive 
institutionalization of cosmopolitan norms makes the egalitarian inclusion of all states increasingly feasible and therefore normatively required.

Our claim about the inevitable procedural injustice of the transition bears some resemblance to Thomas Nagel's speculation that 'the most likely path toward some version of global justice is through the creation of patently unjust and illegitimate global structures of power that are tolerable to the interests of the most powerful current nation-states' (Nagel, 2005:146). However, there is a crucial difference. In Nagel's view, the existence of a global state is a precondition of the demands of global justice to apply, and states have no justice-based reasons to create one (Nagel, 2005, p.133). ${ }^{38}$ By contrast, our view is that principles of justice apply globally, and this constitutes a reason for agents to create the institutions that are necessary to live up to their demands. Our claim about the inevitability of injustice concerns the process of transition only. ${ }^{39}$

We would like to emphasize that our argument suggests only that other states have strong pro tanto moral reasons to support the hegemon in discharging its coordinating role, not that they are morally obligated to do so. But it is precisely this weaker claim that we have been seeking to vindicate. We add, though, that the more the leading state complies with the desiderata of consultation and multilateral decisionmaking mentioned above, the stronger the reasons for supporting it become. Moreover, as the hegemonic transition gradually takes its place and consequently, global institutions and rules slowly emerge, state power, including the power of the hegemon, will be more and more constrained perhaps up until the point when the state system as such will be transcended. Returning to our major point, a salient coordination point necessary to resolve coordination problems triggered by the global institutional reforms can be provided by the hegemon. To the extent such salient option meets the conditions of moral permissibility defined earlier, and thus determines states' transitional duties; 
the determination of duties has a greater moral weight than the problem of unequal distribution of power among states, at least in the transitional period.

\section{Conclusion}

To the extent that our characterization of the normative problem of transition and our interpretation of the HST's empirical analysis are sound, it seems that cosmopolitans can endorse the present liberal world order as the starting point to be built on toward a world order compatible with cosmopolitan principles of justice. Moreover, they can also endorse what we called the hegemonic transition to the extent it complies with our criteria of moral permissibility and as such resolves the problem of moral coordination. The discussion aimed to show that if the empirical conditions obtain, the solution to the problem of transition is available. In the end, we would like to note that our argument has a limited scope. We do not claim that other solutions are inconceivable. We only hold that the hegemonic transition is a morally eligible option and that it has the advantage of being grounded in sufficient empirical evidence. Its potential alternatives should be similarly empirically grounded for a comparative moral evaluation to be possible.

\section{Notes}

${ }^{1}$ For rare philosophical discussions that explicitly engage with the problem of transition see Buchanan (2007), Gilabert (2012), Valentini (2017). Further works that address various aspects of the cosmopolitan transition relevant for our argument include Pasternak (2012), Ulaş (2016, 2017).

2 Throughout the paper we will use the terms a 'hegemonic state' and a 'leading state' interchangeably.

3 We use the generic term 'cosmopolitan transition' as transitioning toward a cosmopolitan world order, and the term 'hegemonic transition' as a specific kind of cosmopolitan transition.

${ }^{4}$ While our argument is an abstract one about the possible role of the hegemonic state (to the extent there is one), it can be plausibly construed as relevant for assessing the 
situation of the United States, which is widely understood to be the current hegemon. See Keohane (2005), and especially Ikenberry (2012). We are grateful to an anonymous reviewer for pressing us on this point.

${ }^{5}$ Note that our usage of the term 'hegemonic transition' differs from the one employed in the IR literature where it stands for transitioning from a world order led by one hegemon, to an order led by another one. See, for instance, Kupchan (2014). On our account, hegemonic transition is about transitioning toward a cosmopolitan, nonhegemonic world order.

${ }^{6}$ For a version of such view see Ypi's account of statist cosmopolitanism in Ypi (2011); Cf. Ulaș (2017)

${ }^{7}$ For cosmopolitan accounts see, for instance, Beitz (1979), Caney (2005), Pogge (2008), Gilabert (2012); For non-cosmopolitan accounts see, for instance, Ronzoni (2013)

${ }^{8}$ For institutional proposals of varying degrees of specificity, see for instance,Held (1995),Archibugi (2008), Marchetti (2012).Of these, Marchetti's federalist approach is the closest to our own.

${ }^{9}$ We say Kantian rather than Kant's since Kant himself was unclear about the favoured kind of global cooperation. For instance, in the Perpetual Peace he endorsed a peaceful voluntary association ("foedus pacificum") among states. See Kant (1999). However, many scholars interpret Kant's cosmopolitan thought as supporting more robust forms of global cooperation. For arguments along these lines see Byrd and Hruschka (2008), Pogge (1988).

${ }^{10}$ One of the advantages of the Kantian account of global justice is that it can explain why global institutions have to be authoritative. For an illuminating discussion see Varden (2011).

${ }^{11}$ However, see the works mentioned in $\mathrm{fn} 1$.

${ }^{12} \mathrm{We}$ are grateful to an anonymous referee for pressing us to clarify the problem of the 'starting point'.

13 In a similar vein, Buchanan defends what he calls 'progressive conservativism' according to which global transformations should start from the most morally acceptable principles of the existing international law. In Buchanan (2007, p. 63); Valentini makes a similar, although less elaborated point in Valentini (2011).

${ }^{14}$ For an account of cosmopolitan transition that takes this consideration seriously, see Pasternak (2012). Pasternak's account is congenial to our own to the extent that it also sees states (and democratic states in particular) as the key agents of the transition. Our account is distinguished by focusing on the potentially privileged role of specific states in light of their superior power and position in the current order.

${ }^{15} \mathrm{We}$ take for granted that states bear a moral obligation to create just global institutions and we are predominantly concerned with how they can discharge their obligations.

${ }^{16}$ For the term, see Garthoff (2010).

${ }^{17}$ For such a proposal see for instance, Archibugi (2008, p. 156).

${ }^{18}$ For the discussion of the inability of the present international order to adapt to changes and self-reform see Snidal (1985).

${ }^{19}$ It should be noted that Keohane is ambivalent about the hegemonic stability theory, especially regarding its crude realist version that focuses entirely on material capabilities. His refined version incorporates the significance of political ideas and attitudes, and internal political structures. See Keohane (2005, pp. 31-35). 
${ }^{20}$ Ikenberry acknowledges that the US has not sought to build multilateral institutions everywhere. Instead, it pursued bilateral interactions in Asia, and it has been entirely willing to unilaterally dominate in Latin America and the Middle East. Initially at least, its multilateralism was restricted to its dealings with Western Europe, where it was instrumental in the creation of what later became the European Union. See Ikenberry (2012, p. 82).

${ }^{21}$ As it happened, for instance, in the case of Western Europe and Japan once they were rebuilt after the destruction of the world wars.

${ }^{22}$ One might point to cases where the hegemon was not necessary for the creation of international institutions. A paradigmatic example is the creation of the International Criminal Court, which not only was created without the hegemon, but the hegemon even sabotaged its creation. But our point is only that hegemonic coordination is a facilitating condition of creating international order, not that it is a necessary one. Surely, the creation of the ICC could have been smoother if the U.S. had been a more willing participant.

${ }^{23}$ I.e. it is among the morally equivalent or at least acceptable alternatives. For an analysis of these types of situations, see Gaus (2012).

24 If a more egalitarian path were to be suddenly feasible, that could constitute a defeating condition, for example.

${ }^{25}$ For an analogous argument in the context of democratic legitimacy, see Waldron (1999, pp. 101-106).

26 This formulation is deliberately echoing Joseph Raz's 'normal justification thesis'. See Raz (1988, p. 53). The hegemon's superior ability to bring about coordination resembles the characteristics of an authority: the fact that the hegemon adopted a morally acceptable alternative itself gives a reason for others to adopt the same, over and above the independent merits of this alternative.

27 Although it significantly goes beyond merely leading by example or being a moral lighthouse. We are grateful to an anonymous reviewer for pressing us on this point.

${ }^{28}$ As an illustration, we can think of the EU's gravitational pull and the neighbouring countries' unqualified desire to join.

${ }^{29}$ We thank an anonymous reviewer for prompting us to clarify our position on coercion.

${ }^{30}$ Luke Ulaş makes the same point in "Cosmopolitanism, Self-Interest and World Government," at p. 106.

${ }^{31}$ Jensen refers to this phenomenon as 'indirect diachronic ability' in Jensen (2009).

${ }^{32}$ This is argued by the proponents of the functional theory of integration. For a seminal work see Mitrany (1948).

${ }^{33}$ This point was suggested to us by one of the referees for this journal.

${ }^{34}$ It is in principle unobjectionable that in federal structures more populous subnational units wield larger political influence.

${ }^{35}$ The problem is further exacerbated by the fact that the poorer states often suffered colonial oppression. While this significantly complicates the moral case for hegemonic transition, it is important to note that rectifying past injustice is typically included in cosmopolitan projects, and therefore we assume that it is addressed in the GPU. We thank an anonymous reviewer for raising this point.

${ }^{36}$ This is a crucial component of standard justifications of the political authority of the state. See for instance Raz's 'service conception' of authority, (1988, p. 67). 
${ }^{37}$ It seems to us that the same considerations apply to a related objection that raises the problem of epistemic injustice that would result from the hegemonic transition, as compared to a process that is more inclusive of a diversity of cultural perspectives. Once again, this strikes us as an important worry that calls for self-restraint on the part of the hegemon as well as making the process as consultative as is consistent with making significant progress. We are grateful for an anonymous reviewer for raising this and related issues.

${ }^{38}$ They may have non-justice-based reasons to do so.

${ }^{39} \mathrm{We}$ thank two anonymous reviewers for pressing us to clarify the relevance of Nagel's point for our account.

\section{Acknowledgments}

We would like to thank Janos Kis, Dragan Kuljanin, Aron Tabor, and two anonymous reviewers for their insightful comments.

\section{Disclosure statement}

No potential conflict of interest is reported by the authors.

\section{ORCID}

Jelena Belic: 0000-0002-5984-6911

Zoltan Miklosi: 0000-0002-4568-6291

\section{About the Authors:}

Jelena Belic is a post-doctoral fellow at the Center for Teaching and Learning, Central European University in Budapest. She received her Ph.D. in political philosophy from the Central European University in 2018. Jelena's research interests include global justice, human rights, and justice in education.

Zoltan Miklosi is an associate professor at Central European University in Budapest. His research areas concern questions of political obligation, distributive justice, and the basis of equal moral status. His recent publications appeared in Oxford Studies in Political Philosophy, Moral Philosophy and Politics, Ethics and Global Politics, Social Theory and Practice, and Res Publica. 


\section{References:}

Archibugi, D. (2008). The Global Commonwealth of Citizens: Toward Cosmopolitan Democracy. Princeton: Princeton University Press.

Beitz, C. (1979). Political Theory and International Relations. Princeton, N.J: Princeton University Press.

Buchanan, A. (2007). Justice, Legitimacy, and Self-Determination: Moral Foundations for International Law. Oxford, New York: Oxford University Press.

Byrd, S. and Hruschka, J. (2008). From the State of Nature to the Juridical State of States. Law and Philosophy,(27), 599-641.

Caney, S. (2005). Justice Beyond Borders. Oxford University Press.

(2006). Cosmopolitan Justice and Institutional Design: An Egalitarian Liberal Conception of Global Governance, Social Theory and Practice,(32),725-56.

Doyle, M. (1983). Kant, Liberal Legacies, and Foreign Affairs. Philosophy \& Public Affairs,(12), 205-35.

Garthoff, J. (2010). Legitimacy Is Not Authority. Law and Philosophy,(29), 669-94.

Gaus, G. (2012). The Order of Public Reason: A Theory of Freedom and Morality in a Diverse and Bounded World. NY: Cambridge University Press.

Gilabert, P. (2012). From Global Poverty to Global Equality: A Philosophical Exploration. Oxford, New York: Oxford University Press.

Held, D. (1995). Democracy and the International Order. In: Held, D. and Archibugi, D. (eds.) Cosmopolitan Democracy: An Agenda for a New World Order. (pp. 96120).Cambridge, Mass.: Polity Press.

Ikenberry, J. (2012). Liberal Leviathan: The Origins, Crisis, and Transformation of the American World Order. Princeton University Press.

Jensen, M. (2009). The Limits of Practical Possibility, Journal of Political Philosophy,(17), $168-84$.

Kant, I. (1999). Toward Perpetual Peace: A Philosophical Project. In: Gregor, M. ed. Practical Philosophy. (pp. 311-52). Cambridge: Cambridge University Press.

Keohane, R. (2005). After Hegemony: Cooperation and Discord in the World Political Economy. Princeton, N.J: Princeton University Press.

Kupchan, C. (2014). The Normative Foundations of Hegemony and The Coming Challenge to Pax Americana, Security Studies,(23), 219-57.

Marchetti, R. (2012). Models of Global Democracy: In Defense of Cosmo-Federalism. In: Archibugi, D., Koenig-Archibugi, M., and Marchetti, R. eds. Global Democracy: Normative and Empirical Perspectives. (pp. 22-46). Cambridge: Cambridge University Press.

Mitrany, D. (1948). The Functional Approach to World Organization, International Affairs (Royal Institute of International Affairs 1944-),(24), 350-63.

Pasternak, A. (2012). Cosmopolitan Justice and the League of Democracies, Critical Review of International Social and Political Philosophy,(15), 649-66.

Pogge, T. (1988). Kant's Theory of Justice, Kant-Studien,(79), 407-433. (1992). Cosmopolitanism and Sovereignty, Ethics,(103), 48-75

. (2008). World Poverty and Human Rights. Cambridge Polity Press.

Raz, J. (1988). The Morality of Freedom. Clarendon Press.

Ronzoni, M. (2013). For (Some) Political and Institutional Cosmopolitanism, (Even If) Against Moral Cosmopolitanism. In: Brock, G. ed. Cosmopolitanism versus NonCosmopolitanism: Critiques, Defenses, Reconceptualizations. Oxford University Press.

Snidal, D. (1985). Coordination versus Prisoners' Dilemma: Implications for International Cooperation and Regimes, The American Political Science Review,(79), 923-42. 
Ulaş, L. (2016). Cosmopolitanism, Self-Interest and World Government, Political Studies,(64), 105-20.

(2017). Transforming (but Not Transcending) the State System? On Statist Cosmopolitanism, Critical Review of International Social and Political Philosophy, (20), 657-76.

Valentini, L. (2011). Justice in a Globalized World: A Normative Framework. Oxford University Press.

. (2017). The Natural Duty of Justice in Non-Ideal Circumstances: On the Moral Demands of Institution Building and Reform, European Journal of Political Theory, 1-22.

Varden, H. (2011). A Kantian Conception of Global Justice, Review of International Studies,(37), 2043-2057.

Waldron, J. (1999). Law and Disagreement. Oxford University Press.

Ypi, L. (2011). Global Justice and Avant-Garde Political Agency. Oxford, New York: Oxford University Press. 